\title{
STRATEGI STRUKTUR MODAL INDUSTRI KEUANGAN NON BANK PADA BISNIS MICROFINANCE (STUDI KASUS PADA PT. XYZ)
}

\author{
CAPITAL STRUCTURE STRATEGY OF THE NON-BANK FINANCIAL INDUSTRY IN THE MICROFINANCE \\ BUSINESS (CASE STUDY AT PT. XYZ)
}

\author{
Epiet Dwi Anggoro $^{* 1}$, Nimmi Zulbainarni*), dan Hendro Sasongko**) \\ *) Sekolah Bisnis, IPB University \\ Jl. Raya Pajajaran, Bogor, Indonesia 16151 \\ **) Fakultas Ekonomi, Universitas Pakuan Bogor \\ Jl. Pakuan PO Box 452 Bogor, Indonesia 16143
}

\begin{abstract}
PT. XYZ is the non-bank institutions with a special task in empowering UMKM that has different funding sources. Funding sources affect the capital structure and business activities. Thus, the development of the capital structure of PT. XYZ needs to be studied, along with the impact of the funding sources types on PT. XYZ strategy and sustainability. Financial reports and in-depth interviews of experts were collected. WACC, SWOT and QSPM used to analyze the capital structure and corporate strategic planning. The results showed that the capital structure of PT XYZ came from capital deposits and government programs, and it increased by getting loans from financial institutions and capital market instruments. The capital market instruments, as the optimal funding source, influenced profit parameters and development agents. PT XYZ's primary chosen strategy was business expansion.
\end{abstract}

Keywords: microfinance, optimal capital structure, QSPM, strategic management, $W A C C$

\begin{abstract}
Abstrak: PT. XYZ adalah salah satu lembaga keuangan non bank yang mendapat tugas khusus dalam pemberdayaan UMKM dan memiliki sumber pendanaan yang berbeda dimana akan mempengaruhi struktur modal dan kegiatan bisnis perusahaan. Oleh karena itu, diperlukan penelitian untuk menganalisa perkembangan capital structure PT. XYZ, pengaruh dan dampak dari jenis sumber-sumber pendanaan terhadap sustainable PT. XYZ, serta strategi perusahaan. Data laporan keuangan dan depth interview pakar diolah untuk menganalisis struktur modal dan perencanaan strategi perusahaan menggunakan Weighted Average Cost of Capital (WACC), SWOT (Strengths, Weakness, Opportunitiess, Threats) dan QSPM (Quantitative Strategic Planning Matriks). Hasil penelitian menunjukkan bahwa struktur modal PT XYZ pada awalnya berasal dari setoran modal dan program pemerintah dan bertambah dengan pinjaman lembaga keuangan dan instrumen pasar modal seiring dengan pertumbuhan usaha. Penggunaan instrumen pasar modal sebagai sumber pendanaan optimal perusahaan memberikan pengaruh dan dampak yang positif pada parameter profit dan development agent. Strategi utama terpilih PT XYZ adalah ekspansi bisnis.
\end{abstract}

Kata kunci: microfinance, struktur modal, QSPM, manajemen strategik, WACC

\footnotetext{
${ }^{1}$ Alamat Korespondensi:

Email: epietanggoro@gmail.com
} 


\section{PENDAHULUAN}

Usaha Mikro Kecil (UMK) merupakan pilar utama perekonomian Indonesia dan teruji mampu bertahan saat krisis ekonomi pada tahun 1998. Para pelaku UMK memiliki nilai dan keunggulan kompetitif dibidang usahanya dan memiliki daya tahan bisnis yang kuat. UMK memiliki kontribusi terhadap PDB Nasional dimana berdasarkan data Bank Indonesia tahun 2005 nilai tersebut menurut harga berlaku pada tahun 2011 sebesar Rp4.321,8 triliun atau 58,05\% sedangkan tahun 2012 sebesar Rp4.869,5 triliun atau 59,08\%.

Peran dan kontribusi dari pelaku UMK ini sangat penting dalam pertumbuhan ekonomi secara nasional. Bappenas (2016) menyatakan bahwa kapasitas UMK di Indonesia untuk menyerap tenaga kerja terus meningkat rata-rata sebesar $5,9 \%$. Nilai penyerapan tenaga kerja ini berperan dalam mengurangi angka pengangguran di Indonesia. Namun, sebagian besar dari tenaga kerja UMK $(88,6 \%)$ masih merupakan tenaga kerja informal pada usaha-usaha berskala mikro. Pertumbuhan UMK juga masih terus terjadi dimana menurut data Bappenas (2016) jumlah UMK pada tahun 2015 diperkirakan mencapai 60,7 juta unit dan sebagian besar merupakan usaha berskala mikro $(98,73 \%)$.

Peranan strategis UMK menginisiasi pendirian PT. XYZ sebagai salah satu BUMN yang mengemban tugas khusus memberdayakan Usaha Mikro, Kecil, Menengah dan Koperasi (UMKMK). Tugas pemberdayaan tersebut dilakukan melalui penyelengaraan jasa pembiayaan dan jasa manajemen, sebagai bagian dari penerapan strategi pemerintah untuk memajukan UMKMK, khususnya merupakan kontribusi terhadap sektor riil. Tujuan dari permberdayaan tersebut guna menunjang pertumbuhan pengusaha-pengusaha baru yang mempunyai prospek usaha dan mampu menciptakan lapangan kerja.

PT. XYZ memiliki beberapa layanan dalam pemberdayaan UMKM, antara lain Layanan Modal Mikro (LMM), yang memberikan layanan pinjaman modal untuk usaha mikro dan kecil yang diluncurkan pada Agustus 2008. Jumlah LMM sudah tersebar dalam 666 unit pembiayaan, dengan cakupan wilayah lebih dari 3.000 kecamatan di Indonesia. Layanan Merekah merupakan layanan pinjaman modal bagi perempuan prasejahtera yang akan membuka UMKM. Produk layanan yang diluncurkan pada 2015 ini telah dilengkapi dengan penyertaan pendampingan usaha. Pelayanan nasabah Merekah dilakukan secara berkelompok, dengan tujuan untuk menghindari terjadinya kredit macet atau Non Performing Loan (NPL) apabila terdapat anggota kelompok yang mengalami kendala dalam kegiatan usaha yang dimiliki. Hal ini yang membedakan PT. XYZ dengan lembaga keuangan lainnya seperti bank.

Dalam melakukan kegiatan operasional bisnis, strategi mengenai struktur modal juga memiliki peran penting. Beberapa dimensi pada struktur modal antara lain jenis instrumen, komposisi dalam struktur modal, dan sumber instrumen. Keputusan struktur modal yang kurang tepat akan menimbulkan biaya modal yang tinggi, sedangkan keputusan struktur modal yang tepat akan dapat merendahkan biaya modal. Porsi modal dan utang (ekuitas) ditentukan oleh perusahaan sesuai dengan posisi keuangan dan kemampuan untuk meningkatkan modal tersebut (Boutilda, 2015). Setiono et al. (2017) melakukan penelitian mengenai pengaruh struktur modal dan modal kerja terhadap kinerja perusahaan. Kebutuhan dana PT. XYZ yang bergerak di bidang keuangan sebagai lembaga keuangan mikro saat ini berasal dari pinjaman pemerintah, perbankan, dan pasar modal. Struktur modal PT. XYZ berbeda dengan lembaga keuangan bank yang mampu menghimpun dana masyarakat yang disebut dana pihak ketiga. PT. XYZ memiliki keterbatasan dalam menghimpun dana hanya pada liabilitas dan ekuitas perusahaan saja. Jumlah liabilitas pada Desember 2017 adalah sebesar Rp9.578,306 miliar. Nilai liabilitas lebih besar dari ekuitas yang dimiliki PT. XYZ yang hanya mencapai Rp1.814,95 miliar (PT. XYZ, 2018).

Besarnya dominasi utang dalam struktur modal menjadikan tantangan PT. XYZ untuk mencapai target di tahun-tahun selanjutnya. PT. XYZ harus berhatihati dalam memenuhi kebutuhan modal, tidak hanya berdasarkan kepada kewajiban untuk ketersediaan dana saja. Selain itu, PT. XYZ memiliki kelebihan berupa fasilitas layanan pinjaman mikro dan peluang nasabah mikro yang jumlahnya tinggi, namun tingkat bunga pinjaman yang cukup tinggi dapat melemahkan PT. XYZ pada persaingan dengan lembaga pendanaan mikro lainnya. Oleh karena itu, perlu studi pengaruh struktur modal untuk mengetahui jenis utang yang dapat meningkatkan keuntungan perusahaan dan sebagai landasan pemilihan jenis pendanaan yang baik digunakan oleh perusahaan. 
Penelitian mengenai pengaruh struktur modal sudah dilakukan di lingkup internasional maupun regional. Pada lingkup internasional, penelitian mengenai pengaruh struktur modal sudah dilakukan di India oleh Bubic dan Jusak (2016) serta Taqi et al. (2016), Kundid (2012) di Kroasia, Johnson (2015) di Sub Sahara Afrika, Sekabira (2013) di Uganda. Penelitian tersebut dilakukan di berbagai jenis lembaga baik pada lembaga microfinance maupun bank. Waweru dan Wanyoike (2016) juga sudah melakukan penelitian mengenai pengaruh struktur modal di lembaga microfinance di Kenya. Dalam lingkup regional, penelitian struktur modal juga sudah dilakukan di berbagai jenis perusahaan seperti Dulababu (2016), Marusya dan Magantar (2016), Violita dan Sulasmiyati (2017), Alima (2015), serta Haninun dan Angelina (2016). Penelitian tersebut dilakukan pada perusahaan food and beverages, Tobacco manufactures, industri tekstil dan garmen, pertambangan, maupun manufaktur. Adapun penelitian di perusahaan yang bergerak di bidang keuangan sudah dilakukan oleh Thalib (2016) pada bank, Abrar dan Javaid (2016), Fersi dan Boujelbéne (2017), Indayani et al. (2017), Omare (2017) pada lembaga keuangan mikro, serta Hasbi (2015) pada lembaga keuangan mikro Islam. Penelitian mengenai pengaruh struktur modal dengan jenis pendanaan seperti pada PT. XYZ belum dilakukan sehingga muncul pertanyaan penelitian sebagai berikut dengan tujuan antara lain menganalisis perkembangan capital structure pada perusahaan microfinance PT. XYZ, menganalisis pengaruh dan dampak dari jenis sumber-sumber pendanaan yang digunakan terhadap sustainable PT. XYZ, serta memberikan strategi perusahaan di industri keuangan non bank PT. XYZ pada bisnis microfinance.

\section{METODE PENELITIAN}

Penelitian ini merupakan studi kasus pada perusahaan yang dipilih dengan menggunakan pendekatan deskriptif dan kuantitatif dengan menggunakan data primer dan data sekunder. Penelitian dilakukan di PT. XYZ yang berlokasi di Jakarta Pusat, waktu penelitian mulai dari bulan Februari 2018 - Oktober 2018. Data yang digunakan dalam penelitian ini adalah data kuantitatif, sumber data merupakan hasil laporan keuangan tahunan PT. XYZ yang sudah diaudit oleh auditor independent. Data laporan keuangan meliputi data laporan laba-rugi, neraca, serta data internal keuangan perusahaan yang telah diolah, yaitu WACOB mulai tahun 2013 sampai tahun 2017.
Data primer yang akan digunakan yakni analisis kualitatif faktor internal dan eksternal dari PT. XYZ menggunakan depth interview dengan para pakar yakni pihak manajemen PT. XYZ (Executive Vice President Bisnis LMM, Kepala Divisi Perencanaan, Riset, dan Afiliasi, serta Kepala Divisi Pengelolaan dan Pengembangan LMM I bagian barat). Data primer diolah untuk menentukan strategi perusahaan di keuangan non bank PT. XYZ pada bisnis microfinance. Melalui wawancara pribadi juga digunakan kueisoner antara lain, Kuesioner Pertama yakni pengisian oleh para pakar mengenai faktor kritis internal dan eksternal dari PT. XYZ, Kuesioner Kedua yakni pemberian skor bobot dan skor peringkat (rating) dari faktor kritis internal dan eksternal (IFE dan EFE) yang diperoleh dari kuesioner pertama, yang akan digunakan sebagai dasar pembuatan matrik IFE dan matrik EFE, serta Kuesioner Ketiga yakni pengisian/pemberian Attractive Score (AS) sebagai dasar analisis QSPM baik untuk faktor kritis internal dan eksternal. Berikut ini adalah rumus penghitungan biaya modal dan struktur modal yang digunakan dalam penelitian ini. Pendekatan yang digunakan untuk menghitung rata-rata tertimbang biaya modal (WACC) adalah dengan MM model. Kedua dalil dari MM dan cara perhitungan nilai perusahaan dan WACC dengan persamaan berikut ini:

\section{Dalil I}

$\mathrm{VL}=\mathrm{VU}+\mathrm{TD}$

Keterangan: VL (Total nilai pasar perusahaan yang memiliki leverage); VU (Total nilai pasar perusahaan yang tidak memiliki leverage); $\mathrm{T}$ (Tarif pajak); D (Total nilai pasar dari hutang).

Nilai perusahaan yang tidak memiliki leverage dapat dirumuskan sebagai berikut:

$\mathrm{S}=\mathrm{VU}=[\operatorname{EBIT}(1-\mathrm{T})] / \mathrm{ksU}$

Keterangan: S (Total nilai perusahaan); VU (Total nilai perusahaan yang tidak memiliki leverage); EBIT (Pendapatan sebelum bunga dan pajak); T (Tarif pajak); $\mathrm{ksU}$ (Biaya ekuitas perusahaan yang tidak memiliki leverage).

\section{Dalil II}

Untuk menghitung biaya ekuitas terhadap perusahaan yang memiliki leverage: 


$$
\mathrm{ksL}=\mathrm{ksU}+(\mathrm{ksU}-\mathrm{kd})(1-\mathrm{T})(\mathrm{D} / \mathrm{S})
$$

Keterangan: ksL (Biaya ekuitas perusahaan yang memiliki leverage); $\mathrm{ksU}$ (Biaya ekuitas perusahaan non leverage); T (Tarif pajak); D (Total nilai pasar dari hutang); S (Total nilai pasar perusahaan).

Maka bisa didapatkan rata-rata tertimbang biaya modal:

$$
\mathrm{WACC}=(\mathrm{D} / \mathrm{T})(\mathrm{kd})(1-\mathrm{T})+(\mathrm{S} / \mathrm{V}) \mathrm{ks}
$$

Keterangan: D (Total nilai pasar dari hutang); V (Total nilai pasar dari ekuitas); kd (Biaya hutang sebelum pajak); T (Tarif pajak); S (Total nilai pasar perusahaan); V (Total nilai pasar dari perusahaan); ks (Biaya ekuitas).

Tahap selanjutnya setelah perhitungan nilai perusahaan dan WACC adalah perhitungan struktur modal optimal. Analisa penghitungan struktur modal optimal dilakukan dengan simulasi menggunakan WACOB. Nilai WACOB untuk sumber pendanaan dari pasar modal, adalah dihitung dari jumlah total biaya bunga dari pasar modal dibagi total hutang pasar modal PT.XYZ pada tahun tersebut. Rumus yang digunakan untuk pasar modal yakni sebagai berikut:

\section{WACOB Pasar modal $=$ JPi $\times$ RPi}

Keterangan: JPi (nominal dari setiap seri obligasi yang diterbitkan oleh PT. XYZ); RPi (tingkat bunga setiap seri obligasi yang diterbitkan oleh PT. XYZ); n (jumlah dari seri obligasi yang diterbitkan oleh PT. XYZ).

Nilai WACOB untuk sumber pendanaan dari perbankan, adalah dihitung darijumlah total biaya bunga dari hutang perbankan dibagi total nominal hutang perbankan PT. $\mathrm{XYZ}$ pada tahun tersebut. Rumus yang digunakan, yakni sebagai berikut:

WACOB perbankan $=\mathrm{JBi} \times \mathrm{RBi}$

Keterangan: RBi (tingkat bunga pinjaman bank per fasilitas pinjaman bank PT. XYZ); JBi (nominal pinjaman bank per fasilitas pinjaman bank PT. XYZ); n ( jumlah dari fasilitas pinjaman bank PT. XYZ).

Tahapan setelah PT. XYZ melakukan analisis kinerja keuangan dan struktur modal adalah merumuskan strategi perusahaan. Analisis keuangan digunakan sebagai pendukung dari perumusan strategi pada PT. XYZ. Kerangka pemikiran disajikan pada Gambar 1. PT. XYZ melakukan ekspansi bisnis yang jangkauannya terus berkembang setiap tahunnya. Untuk mendukung kegiatan operasional dan bisnisnya, PT. XYZ memerlukan sumber pendanaan maka diperlukan manajemen struktur modal yang optimal. PT. XYZ merupakan BUMN dan lembaga keuangan non bank yang tidak bisa menghimpun dana dari pihak ke-tiga. Kinerja keuangan perusahaan selama 5 tahun terakhir dilakukan dengan menggunakan rasio kinerja keuangan dan WACC. Warsawinangun et al. (2014) menggunakan WACC pada PT. Astra Internasional dan anak perusahaannya. Biaya yang timbul dalam penyediaan dana atau harus diperhatikan dalam menentukan komposisi struktur pendanaan. Oleh karena itu, diperlukan manajemen cost of capital. Selanjutnya penghitungan cost of debt juga dilakukan dengan menggunakan simulasi WACOB. Selain itu juga diperlukan strategi perusahaan yang nantinya akan dituangkan dalam implikasi manajerial. Hipotesis pada penelitian ini yaitu untuk melihat pengaruh struktur modal terhadap sustainable perusahaan.

\section{HASIL}

\section{Perkembangan Capital Structure pada Perusahaan Microfinance PT. XYZ}

Kinerja keuangan dalam bentuk laporan laba rugi dan neraca dalam lima tahun terakhir 2013 - 2017. disajikan pada Tabel 1. Beban pokok penjualan pada mengalami tren peningkatan kecuali pada tahun 2015 dan 2016 mengalami penurunan walaupun terdapat kenaikan pendapatan setiap tahun. Hal ini disebabkan terjadinya efisiensi dari beban pokok penjualan yang merupakan bunga dari pinjaman yang menjadi sumber pendanaan PT. XYZ. Pada tahun 2017, baik pendapatan maupun beban pokok penjualan meningkat cukup pesat yang disebabkan adanya perkembangan kapasitas usaha. Hal tersebut ditunjukkan dengan target nasabah 2017 yang tercapai yakni sebesar 2 juta nasabah dari sebelumnya 700 ribu nasabah pada tahun 2016.

Tarif beban bunga dan pendapatan sebelum pajak dalam lima tahun terakhir sempat mengalami penurunan pada tahun 2016 namun terdapat kenaikan pada 2017 walaupun tidak terlalu besar seperti yang terlihat pada Tabel 2. Adapun nilai saldo pinjaman dan beban bunga dari tahun 2015 hingga 2017 terus meningkat seiring 
dengan meningkatnya kapasitas bisnis PT. XYZ. Nilai beban pajak juga terus menurun, terutama pada tahun 2016 dengan nilai 4,9 miliar rupiah yang disebabkan oleh adanya pajak tangguhan sebesar 11,6 miliar rupiah.

Secara keseluruhan, posisi neraca keuangan perusahaan yang menunjukkan nilai aset, liabilitas dan ekuitas dalam lima tahun terakhir dapat dilihat pada Tabel 3. PT. XYZ memiliki total aset sebesar 10,4 triliun rupiah untuk tahun yang berakhir pada tanggal 31 Desember 2017 yang terdiri dari aset lancar dan tidak lancar masing-masing sebesar 10,1 triliun rupiah dan 290 miliar rupiah. Nilai aset ini meningkat dibandingkan tahun 2016 yang sebesar 7,1 triliun rupiah, dan tahun 2015 sebesar 5,7 triliun rupiah. Pada sisi kewajiban dan ekuitasnya tahun 2017, terdiri dari kewajiban jangka pendek sebesar 7,9 triliun rupiah, kewajiban jangka panjang 662 miliar rupiah dan jumlah ekuitas sebesar 1,8 triliun rupiah.

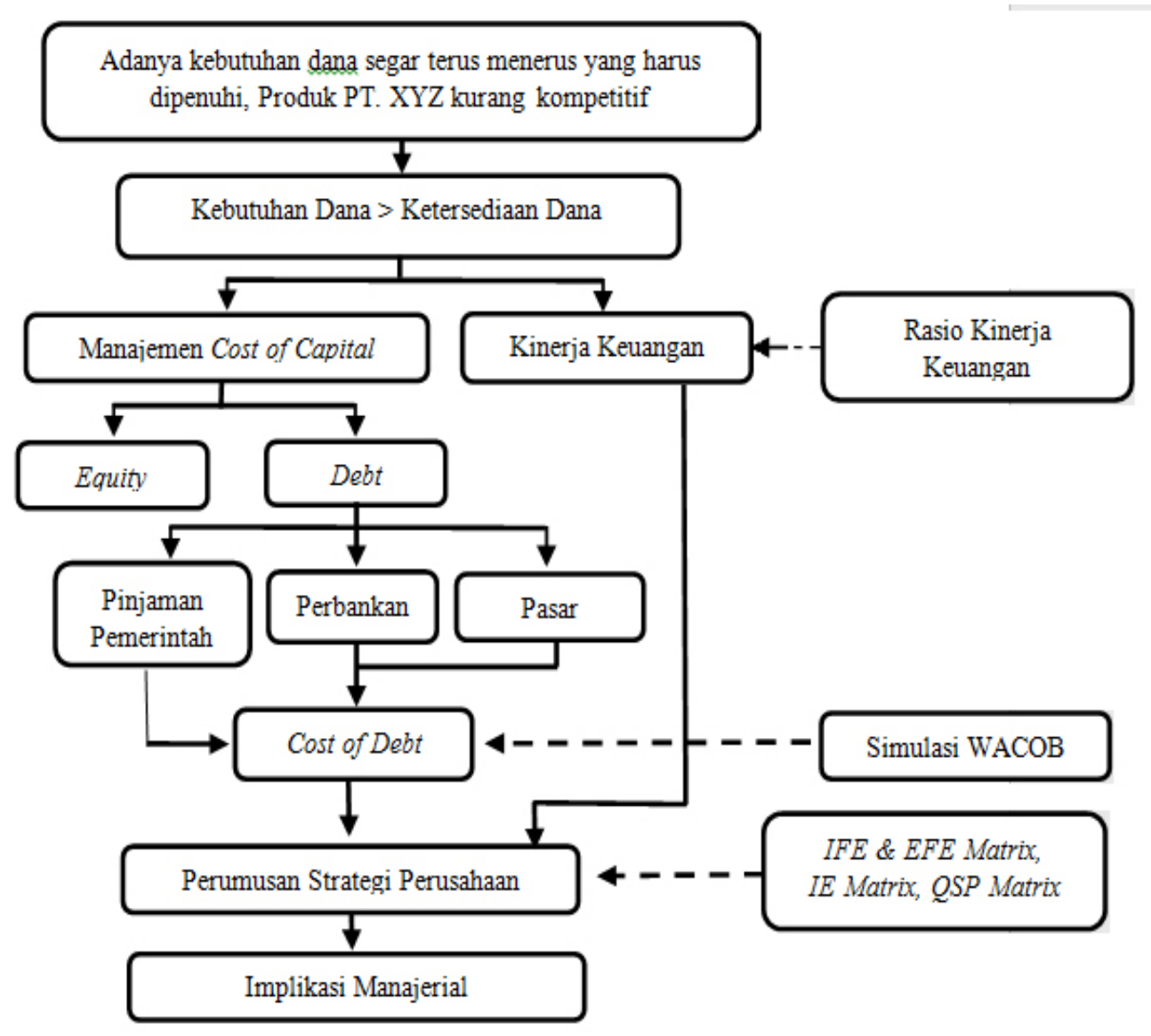

Gambar 1. Kerangka Pemikiran penelitian

Tabel 1. Laporan laba rugi untuk periode tahun 2013 - 2017

\begin{tabular}{lccccc}
\hline Laporan Laba-Rugi & 2013 & 2014 & 2015 & 2016 & 2017 \\
\hline Penjualan bersih & 933,0 & $1.048,0$ & $1.123,9$ & $1.229,9$ & $1.914,8$ \\
Beban pokok penjualan & $(295,1)$ & $(371,1)$ & $(370,5)$ & $(363,5)$ & $(600,2)$ \\
Laba bruto & 637,9 & 676,8 & 753,4 & 866,4 & $1.314,7$ \\
Beban usaha & $(620,4)$ & $(676,2)$ & $(726,7)$ & $(882,5)$ & $(1.438,7)$ \\
Laba usaha & 17,5 & 0,6 & 26,8 & $(16,0)$ & $(124,0)$ \\
Pendapatan lainnya & 60,4 & 104,2 & 80,5 & 69,2 & 177,5 \\
Laba sebelum pajak & 77,9 & 104,8 & 107,3 & 53,2 & 53,5 \\
Beban pajak & $(32,6)$ & 44,2 & $(43,1)$ & $(5,0)$ & $(18,1)$ \\
Laba bersih & 45,3 & 60,6 & 64,2 & 48,2 & 35,4 \\
\hline
\end{tabular}


Tabel 2. Beban bunga dan beban pajak untuk periode tahun 2013-2017

\begin{tabular}{lccccc}
\hline Beban Bunga dan Pajak & 2013 & 2014 & 2015 & 2016 & 2017 \\
\hline Saldo Pinjaman - 31 Des & $3.947,2$ & $3.996,8$ & $3.602,4$ & $4.924,8$ & $7.929,5$ \\
Beban Bunga & 295,1 & 371,1 & 370,5 & 363,5 & 600,2 \\
Tarif Bunga Pinjaman & $7,48 \%$ & $9,29 \%$ & $10,28 \%$ & $7,38 \%$ & $7,57 \%$ \\
Pendapatan Sebelum Pajak & 77,9 & 104,8 & 107,3 & 53,2 & 53,5 \\
Beban Pajak & 32,6 & 44,2 & 43,1 & 5,0 & 18,1 \\
\hline
\end{tabular}

Tabel 3. Laporan posisi keuangan untuk tahun yang berakhir 31 Des 2013-2017

\begin{tabular}{lccccc}
\hline Laporan Posisi Keuangan (Miliar Rp) & 2013 & 2014 & 2015 & 2016 & 2017 \\
\hline Aset Lancar & $4.891,7$ & $5.017,5$ & $5.626,0$ & $7.051,7$ & $10.135,4$ \\
Aset Tidak Lancar & 62,2 & 75,1 & 91,1 & 110,8 & 290,4 \\
Jumlah Aset & $4.953,9$ & $5.092,6$ & $5.717,1$ & $7.162,5$ & $10.425,8$ \\
Liabilitas Jangka Pendek & $4.008,3$ & $4.034,0$ & $3.628,9$ & $4.945,1$ & $7.957,7$ \\
Liabilitas Jangka Panjang & 344,7 & 396,3 & 367,3 & 481,4 & 662,4 \\
Jumlah Liabilitas & $4.353,0$ & $4.430,2$ & $3.996,2$ & $5.426,4$ & $8.620,1$ \\
Jumlah Ekuitas & 600,9 & 662,4 & $1.721,0$ & $1.736,1$ & $1.805,7$ \\
Jumlah Liabilitas dan Ekuitas & $4.953,9$ & $5.092,6$ & $5.717,1$ & $7.162,5$ & $10.425,8$ \\
\hline
\end{tabular}

Tingkat likuiditas perusahaan yang dicerminkan oleh current ratio dan quick ratio yang mengalami peningkatan hingga tahun 2015. Namun, mengalami penurunan menurun hingga tahun 2017. Hal ini disebabkan adanya peningkatan utang usaha yang termasuk ke dalam jangka pendek pada tahun 2016 dan 2017. Oleh karena itu, nilai current ratio dan quick ratio mengalami selama dua tahun terakhir. Tingkat profitabilitas perusahaan dalam 5 tahun terakhir ini mengalami penurunan, yang sebagian besar disebabkan oleh peningkatan kapasitas usaha perusahaan. Dengan berpindahnya fokus perusahaan untuk meningkatkan kapasitas usaha maka biaya yang dikeluarkan untuk investasi akan meningkat sehingga laba yang diperoleh akan turun.

Nilai fixed asset turnover ratio sejak tahun 2013 hingga 2017 cenderung mengalami penurunan. Adapun nilai total asset turnover ratio sejak tahun 2013 hingga 2017 terdapat kenaikan pada tahun 2014 namun kembali turun hingga tahun 2017. Rasio jumlah hutang ataupun kewajiban terhadap ekuitas maupun asset PT. XYZ meningkat drastis di tahun 2017, hal ini disebabkan pinjaman jangka pendek atau utang usaha yang dilakukan untuk peningkatan kapasitas usaha. Analisisrasio kinerja keuangan PT. XYZ dalam jangka waktu lima tahun terakhir disajikan pada Tabel 4.

\section{Pengaruh dan Dampak dari Jenis Sumber-sumber Pendanaan yang Digunakan terhadap Sustainable PT. XYZ}

Analisis struktur modal optimal akan dibagi dalam dua bagian utama. Bagian yang pertama akan menganalisis kinerja keuangan dalam lima tahun terakhir dimana nilai perusahaan dan biaya modal akan dihitung dan dianalisis. Hasil dari perhitungan ini akan menampilkan gambaran perbedaan struktur modal dengan nilai perusahaan dan biaya modal yang berbeda untuk masing masing tahun. Sedangkan bagian yang kedua dari analisis akan coba menghitung struktur modal optimal. Hasil dari analisis bagian ini akan menampilkan proporsi hutang terhadap modal dan struktur modal yang akan meminimalkan biaya modal secara keseluruhan.

Analisis struktur modal dilakukan menggunakan WACC atau rata rata tertimbang biaya modal (Weighted Average Cost of Capital). Hasil penghitungan nilai WACC dengan pendekatan tradisional dan Modigliani dan Miller disajikan pada Tabel 5. Hasil penghitungan pada Tabel 5 menggambarkan bahwa nilai perusahaan meningkat seiring dengan peningkatan debt ratio. Pada tahun 2016 dan 2017 nilai perusahaan meningkat karena adanya ekspansi bisnis sehingga terdapat peningkatan nilai hutang PT. XYZ. Angka rata-rata tertimbang biaya modal PT. XYZ pada tahun 2016 dan 2017 lebih rendah dibandingkan dengan tahun sebelumnya. Hal ini disebabkan faktor proporsi hutang dari PT. XYZ. 
Tabel 4. Analisa rasio kinerja keuangan PT. XYZ 2013-2017

\begin{tabular}{lccccc}
\hline Ratio Analysis & 2013 & 2014 & 2015 & 2016 & 2017 \\
\hline Liquidity & & & & & \\
Current Ratio & 1,42 & 1,44 & 1,82 & 1,60 & 1,35 \\
Quick Ratio & 1,22 & 1,24 & 1,54 & 1,42 & 1,26 \\
Profitability & & & & & \\
Return On Asset & 0,01 & 0,01 & 0,01 & 0,01 & 0,00 \\
Return On Equity & 0,08 & 0,09 & 0,04 & 0,03 & 0,02 \\
Gross Profit Margin & 0,34 & 0,35 & 0,35 & 0,28 & 0,25 \\
Operating Profit Margin & 0,02 & 0,00 & 0,02 & $(0,01)$ & $(0,06)$ \\
Net Profit Margin & 0,05 & 0,06 & 0,06 & 0,04 & 0,02 \\
Activity & & & & & \\
Fixed Asset Turnover & 22,51 & 22,00 & 17,71 & 15,17 & 12,03 \\
Total Asset Turnover & 0,19 & 0,21 & 0,20 & 0,17 & 0,18 \\
Solvability & & & & & \\
Debt To Equity & 6,67 & 6,09 & 2,11 & 2,85 & 4,41 \\
Debt To Asset & 0,81 & 0,79 & 0,63 & 0,69 & 0,76 \\
Deb To EBITDA & 11,91 & 10,33 & 8,47 & 12,58 & 14,08 \\
Total Liability To Equity & 7,24 & 6,69 & 2,32 & 3,13 & 4,77 \\
Total Liability To Assets & 0,88 & 0,87 & 0,70 & 0,76 & 0,83 \\
Times Interest Earned & 1,06 & 1,00 & 1,07 & 0,96 & 0,79 \\
EBITDA To Interest Exp & 1,14 & 1,05 & 1,16 & 1,08 & 0,94 \\
\hline
\end{tabular}

Tabel 5. Kaitan antara Debt Ratio, Firm Value dan WACC - pendekatan tradisional dan modigliani-miller

\begin{tabular}{lcccccc}
\hline Tahun & DAR & EBIT & \multicolumn{2}{c}{ Tradisional } & \multicolumn{2}{c}{ Modigliani-Miller } \\
\cline { 3 - 6 } & & & Firm Value $(\mathrm{V})$ & WACC & Firm Value $(\mathrm{V})$ & WACC \\
\hline 2013 & $80 \%$ & 373.038 .130 .687 & 4.678 .570 .246 .882 & $5,98 \%$ & 4.488 .397 .165 .106 & $5,49 \%$ \\
2014 & $78 \%$ & 475.896 .894 .286 & 4.742 .279 .623 .795 & $7,53 \%$ & 4.385 .556 .640 .852 & $6,98 \%$ \\
2015 & $63 \%$ & 477.806 .509 .071 & 4.365 .956 .759 .765 & $8,21 \%$ & 4.300 .543 .567 .606 & $8,09 \%$ \\
2016 & $69 \%$ & 416.694 .349 .473 & 5.515 .933 .974 .328 & $5,67 \%$ & 5.861 .135 .344 .695 & $5,32 \%$ \\
2017 & $76 \%$ & 653.643 .601 .555 & 8.523 .596 .794 .476 & $5,75 \%$ & 9.245 .071 .728 .857 & $5,37 \%$ \\
\hline
\end{tabular}

Pada PT. XYZ terdapat perhitungan internal beban dari kegiatan pendanaan yang menggunakan data yang dimiliki oleh divisi keuangan. Hasil penghitungan beban dari kegiatan pendanaan tersebut yakni WACOB atau weighted of average cost of borrowing. WACOB merupakan proporsi dari biaya rata-rata tertimbang dari setiap jenis sumber pendanaan yang digunakan oleh PT. XYZ, baik dana yang berasal dari perbankan maupun pasar modal. Simulasi berbagai tingkatan jenis pendanaan yang digunakan untuk tahun 2013 menghasilkan nilai WACOB terendah, yakni $9,6 \%$ berada pada komposisi $100 \%$ ratio pinjaman pasar modal. Simulasi yang sama dilakukan untuk periode selanjutnya, yaitu dari tahun 2014 - 2017.
Hasil simulasi dari berbagai tingkatan jenis pendanaan yang digunakan untuk tahun 2013 hingga 2017 menunjukkan bahwa komposisi jenis pendanaan terbaik adalah dengan menggunakan dana yang bersumber dari pasar modal. Hal tersebut didukung dengan nilai WACOB yang semakin rendah dengan naiknya persentase dana yang berasal dari pasar modal. Rendahnya nilai biaya yang muncul dengan penggunaan dana yang bersumber dari pasar modal akan menurunkan nilai WACOB. Adapun nilai WACOB terendah, yakni pada tahun 2013 dimana nilai WACOB merupakan nilai yang paling kecil. 


\section{Strategi Perusahaan di Keuangan non Bank PT. XYZ pada Bisnis Microfinance}

Hasil wawancara pribadi dengan pakar yang kemudian didapatkan faktor kritis dan dituangkan dalam Matrik IFE/EFE. Total nilai dari faktor internal adalah sebesar 2,95 . Faktor penting yang dilihat dari bobot yang paling besar adalah faktor SDM yang aman dengan bobot 0,16 dengan nilai skor 0,63 . Faktor kekuatan dengan rating tertinggi (4) yang harus terus ditingkatkan oleh PT. XYZ adalah Program Pengembangan Kapasitas Usaha, Pelayanan cepat, dan SDM yang kompeten. Faktor kelemahan yang juga harus diperhatikan oleh PT. XYZ adalah tidak bisa himpun dana pihak ketiga dan nilai DER. Total nilai dari faktor eksternal adalah sebesar 2,70. Faktor penting yang dilihat dari bobot yang paling besar adalah potensi UMKM. Faktor potensi UMKM dengan bobot, yaitu 0,21 dengan nilai skor 0,83 . Faktor peluang dengan rating tertinggi (4) yang dapat dimanfaatkan oleh PT. XYZ, yaitu potensi UMKM dan dukungan pemerintah terhadap mikro. PT. XYZ juga harus menghadapi ancaman eksternalnya yaitu pembayaran dari nasabah bermasalah.

Idealnya skor rata-rata dari matrik IFE/EFE adalah $2,50$ dalam evaluasi internal (skor $=2,95)$ dan eksternal $($ skor $=2,70)$ dapat dilihat bahwa skor totalnya lebih besar dari 2,50 (> 2,50). Hal ini menunjukkan bahwa strategi perusahaan telah dirancang dengan baik untuk memenuhi peluang dan mempertahankan diri dari ancaman lingkungan eksternalnya serta menunjukkan bahwa perusahaan tidak lemah terhadap pesaingnya.

Tahapan perumusan strategi selanjutnya, yaitu matching stage dengan matriks SWOT. Pada meningkatkan kekuatan dan memaksimalkan peluang terdapat pilihan strategi ekspansi bisnis dan branding perusahaan sedangkan untuk menekan kelemahan dan memaksimalkan peluang terdapat pilihan strategi penyertaan modal negara. Adapun untuk meningkatkan kekuatan dan meminimalkan ancaman terdapat pilihan strategi upgrade fasilitas nasabah sedangkan untuk menekan kelemahan dan meminimalkan ancaman terdapat pilihan strategi memberikan produk untuk retensi nasabah sehingga loyalitas nasabah bias terjaga dan mitigasi risiko nasabah bermasalah dengan buffering dari angsuran (Dana Cadangan Angsuran).

Dengan mengetahui posisi PT. XYZ maka dalam IE matrik yaitu pada kuadran $\mathrm{V}$ jaga dan pelihara. Selanjutnya, diperlukan strategi pembanding untuk menentukan strategi prioritas sehingga diperlukan matriks SWOT. Berdasarkan depth interview dengan pakar, maka strategi yang dipilih, yakni strategi S-O atau strength-opportunity. Hal ini disebabkan kondisi internal PT. XYZ yang kuat dan peluang yang masih luas sehingga strategi tersebut dipilih. Tahapan selanjutnya, yakni analisis QSPM yang digunakan untuk menentukan daya tarik relatif dari gambaran strategi yang dihasilkan dari Matrik SWOT pada Tabel 6 sehingga dapat dipilih strategi utama yang paling baik untuk diimplementasikan. Hasil analisis perumusan strategi alternatif menggunakan Quantitative Strategic Planning Matrix (QSPM), diperoleh tiga strategi yang didasari pada posisi strategis PT. XYZ.

Berdasarkan keseluruhan strategi alternatif yang telah didapatkan dalam urutan tingkat prioritas untuk seluruh strategi yang disajikan pada Tabel 7. Adapun terdapat tiga strategi yang dapat direkomendasikan. Strategi Prioritas 1, yakni Strategi penetrasi pasar, yaitu melakukan ekspansi bisnis dengan menambah jumlah kantor sehingga menciptakan jumlah nasabah yang lebih banyak dengan nilai TAS $=7,07$. Strategi ini lebih berfokus pada peningkatan kapasitas usaha dan pendukungnya seperti SDM dan infrastruktur agar dapat memenuhi kebutuhan nasabah.

Strategi Prioritas 2, yakni Strategi pengembangan produk melakukan improvement terhadap sumber pendanaan baik dari tipe sumber pendanaan dan jumlahnya dengan nilai TAS $=6,81$. Strategi tersebut dilakukan dengan tujuan mempertahankan posisi yang sudah ada saat ini, agar PT. XYZ tetap dapat sustainable dalam kegiatan usaha pendanaan. Strategi Prioritas 3 yakni Strategi penetrasi pasar baru dengan melakukan branding PT. XYZ dengan menunjukkan uniqueness yang tidak dimiliki oleh kompetitor dengan nilai $\mathrm{TAS}=5,97$. Strategi ini bertujuan untuk memanfaatkan peluang dan tetap sustainable dalam kegiatan usaha pendanaan.

Berdasarkan hasil analisis, ada beberapa hal yang perlu diperhatikan oleh manajemen dalam mempertimbangkan struktur modal optimal yang akan berimplikasi pada sustainable perusahaan. Hal ini disebabkan oleh jenis kegiatan bisnis dari PT. XYZ yang merupakan pendanaan mikro sehingga baik produk maupun sumber kegiatan bisnis perusahaan adalah uang. Oleh karena itu, pendanaan merupakan darah utama dari kegiatan bisnis perusahaan agar tetap sustainable. 
Tabel 6. Matrik SWOT

\begin{tabular}{|c|c|c|}
\hline Matriks Tows & $\begin{array}{l}\text { Strength } \\
\text { Terdapat program PKU (S1) } \\
\text { Adanya hilirisasi produk nasabah (S2) } \\
\text { SDM yang kompeten (S3) } \\
\text { Infrastruktur yang lengkap dan tersebar } \\
\text { nasional (S4) } \\
\text { Pelayanan cepat (S5) }\end{array}$ & $\begin{array}{l}\text { Weakness } \\
\text { Tidak bisa himpun dana pihak ke tiga } \\
\text { (W1) } \\
\text { Biaya pendanaan tinggi (W2) } \\
\text { Nilai DER (W3) } \\
\text { Turnover SDM (W4) }\end{array}$ \\
\hline $\begin{array}{l}\text { Oportunity } \\
\text { Potensi UMKM (nasabah) }(\mathrm{O} 1) \\
\text { Tren wirausaha }(\mathrm{O} 2) \\
\text { Dukungan program pemerintah } \\
\text { terhadap mikro }(\mathrm{O} 3)\end{array}$ & $\begin{array}{l}\text { (Strength-Opportunity) } \\
\text { Ekspansi bisnis (S4, O1, O3) } \\
\text { Branding perusahaan }(\mathrm{S} 1, \mathrm{~S} 2, \mathrm{O} 2, \mathrm{O} 3)\end{array}$ & $\begin{array}{l}\text { (Weaknes-Opportunity) } \\
\text { Penyertaan Modal Negara (W1, O3) }\end{array}$ \\
\hline $\begin{array}{l}\text { Threat } \\
\text { Take over nasabah (T1) } \\
\text { Pembayaran dari nasabah bermasalah } \\
\text { (T2) } \\
\text { Turnover SDM (T3) } \\
\text { Ada jeda waktu pencairan (T4) } \\
\text { Sumber dana pemerintah tidak selalu } \\
\text { tersedia (T5) }\end{array}$ & $\begin{array}{l}\text { (Strength-Threat) } \\
\text { Upgrade fasilitas nasabah }(\mathrm{S} 5, \mathrm{~T} 1)\end{array}$ & $\begin{array}{l}\text { (Weakness-Threat) } \\
\text { Memberikan produk untuk retensi } \\
\text { nasabah sehingga loyalitas nasabah } \\
\text { bias terjaga (W1, T1) } \\
\text { Mitigasi risiko nasabah bermasalah } \\
\text { dengan buffering dari angsuran (Dana } \\
\text { Cadangan Angsuran) (W1, T2) }\end{array}$ \\
\hline
\end{tabular}

\section{Tabel 6. Matrik SWOT}

\begin{tabular}{|c|c|c|c|c|c|c|}
\hline \multirow{2}{*}{ Faktor kunci sukses } & \multirow{2}{*}{ Bobot } & \multicolumn{2}{|c|}{ Strategi I } & \multicolumn{2}{|c|}{ Strategi II } & Strategi III \\
\hline & & AS & TAS & AS & TAS & TAS \\
\hline
\end{tabular}

\section{Kekuatan}

Adanya program pengembangan kapasitas usaha

$\begin{array}{lllllll}0,14 & 2 & 0,27 & 3 & 0,41 & 4 & 0,54 \\ 0,12 & 1 & 0,12 & 3 & 0,36 & 4 & 0,48 \\ 0,14 & 4 & 0,57 & 4 & 0,57 & 4 & 0,57 \\ 0,13 & 3 & 0,38 & 4 & 0,51 & 3 & 0,38 \\ 0,11 & 4 & 0,45 & 4 & 0,45 & 4 & 0,45 \\ & & & & & & \\ 0,09 & 4 & 0,36 & 3 & 0,27 & 1 & 0,09 \\ 0,06 & 4 & 0,25 & 4 & 0,25 & 1 & 0,06 \\ 0,07 & 4 & 0,28 & 3 & 0,21 & 1 & 0,07 \\ 0,06 & 4 & 0,24 & 3 & 0,18 & 2 & 0,12 \\ 0,08 & 4 & 0,33 & 4 & 0,33 & 4 & 0,33\end{array}$

\section{Peluang}

Potensi UMKM (nasabah)

$\begin{array}{lllllll}0,24 & 4 & 0,96 & 4 & 0,96 & 3 & 0,72 \\ 0,16 & 3 & 0,48 & 4 & 0,64 & 4 & 0,64 \\ 0,15 & 3 & 0,45 & 4 & 0,60 & 4 & 0,60\end{array}$

Satu-satunya BUMN ultramikro

\section{Ancaman}

\begin{tabular}{|c|c|c|c|c|c|c|c|}
\hline Take over nasabah & 0,13 & 4 & 0,51 & 3 & 0,38 & 2 & 0,26 \\
\hline Pembayaran dari nasabah bermasalah & 0,18 & 4 & 0,71 & 2 & 0,36 & 2 & 0,36 \\
\hline Turnover SDM & 0,14 & 3 & 0,43 & 4 & 0,58 & 2 & 0,29 \\
\hline Nilai DER & 0,14 & 2 & 0,27 & 3 & 0,41 & 4 & 0,54 \\
\hline Total & 2,00 & & 6,81 & & 7,07 & & 5,97 \\
\hline
\end{tabular}


Sebagai BUMN yang bergerak pada bidang microfinance, terdapat dua aspek yang perlu dijadikan acuan dalam setiap penentuan langkah strategis, yaitu profit center dan agent of development, karena adanya intervensi pemerintah sebagaimana teori agensi yang dikemukakan oleh Alijoyo et al. (2014). Dua aspek tersebut penting untuk diperhatikan untuk mencapai keberlanjutan bisnis perusahaan. Dari hasil karya ilmiah ini, peneliti menyampaikan beberapa implikasi yang dapat menjadi perhatian bagi perusahaan. Implikasi yang diberikan dibagi disampaikan sesuai dengan dua aspek perusahaan sebagaimana disebutkan sebelumnya.

\section{Implikasi Manajerial}

\section{Profit Centre}

Dalam mendukung strategi perusahaan, terlebih dengan karakteristik pembiayaan mikro dan ultra mikro, maka struktur modal menjadi sangat penting khususnya terkait likuiditas. Pemilihan struktur modal terbaik dengan biaya yang rendah menjadi pilihan yang paling rasional selain setoran modal pemerintah dalam bentuk Penyertaan Modal Negara (PMN) yang apabila dilihat dari sisi cost, tidak memiliki biaya sama sekali. Dengan kondisi tersebut, PT XYZ direkomendasikan untuk memilih sumber pendanaan dalam bentuk liabilitas dari pasar modal. Secara historikal pendanaan ini menimbulkan biaya yang relatif rendah dibandingkan dengan sumber pendanaan liabilitas lainnya. Hal ini dapat lebih memaksimalkan profit perusahaan.

Seiring dengan volume sumber pendanaan pasar modal, perbaikan peringkat investasi perusahaan menjadi hal yang perlu dilakukan selanjutnya guna menghasilkan pembayaran kupon yanglebih rendah. Halini disebabkan oleh pembayaran kupon dan pengembalian pokok ketika waktu jatuh tempo jumlahnya yang cukup besar. Apabila tidak dipersiapkan ketersediaan dana dengan baik dan matang, tentunya akan memberatkan cash flow perusahaan. Oleh karena itu, PT. XYZ perlu melakukan tindakan yang dapat disebut juga dengan sinking finance ketika mendapatkan dana dari pasar modal. Penentuan waktu penerbitan instrumen pasar modal juga perlu diperhatikan sehingga dapat menarik minat pasar. Namun demikian, dengan sumber pendanaan pasar modal tersebut dan struktur modal yang dimiliki saat ini, PT XYZ tetap harus memiliki prudent mechanism sehingga rasio solvabilitas perusahaan, misalnya Debt to Equity (DER), tetap terjaga dalam level yang dapat dimitigasi. Beberapa usaha yang dapat dilakukan untuk menurunkan nilai DER antara lain dengan menambah modal berupa saham atau menurunkan nilai utang yang dimiliki oleh perusahaan.

\section{Agent of Development}

Dengan mempertimbangkan tingginya market UMKM yang belum tergarap secara optimal $(60-70 \%)$, dan dalam rangka ketersediaan dana yang cepat bagi usaha UMKM maka strategi ekspansi bisnis dengan membuka kantor cabang baru menjadi implikasi dari penelitian ini. Hal tersebut didukung dengan sifat kegiatan bisnis mikro dan ultra mikro yang membutuhkan kontrol, nasabah yang tersebar di pelosok, dan pola 'jemput bola' yang dirasa lebih efisien.

Peneliti melihat secara historikal pembukaan kantor cabang baru telah memberikan banyak manfaat baik dari sisi finansial, terlebih lagi dari sisi pertumbuhan dan pengembangan UMKM. Dengan pembukaan cabang baru, jangkauan kepada masyarakat akan semakin besar. Hal yang harus diperhatikan dalam pembukaan cabang baru adalah penentuan lokasi yang didahului adanya analisa kelayakan yang baik, adanya usaha sektor riil masyarakat, dan adanya infrastruktur dasar. Selain itu, pihak UMKM juga perlu mendapatkan dukungan aspek finansial berupa kredit pembiayaan yang rendah. Dengan rendahnya bunga pinjaman yang didapatkan UMKM nantinya akan mendukung perkembangan UMKM. Selain itu juga akan mendukung program pemerintah dalam pemberdayaan UMKM dan meningkatkan kesejahteraan masyarakat. Oleh karena itu, pemerintah sebagai regulator juga perlu memberikan dukungan yang berkelanjutan kepada PT. XYZ berupa pemberian Penyertaan Modal Negara (PMN) setiap tahunnya secara berkelanjutan. Data nominatif, jenis usaha, sektor, nasabah UMKM PT. XYZ dapat menjadi informasi dan basis data bagi pemerintah untuk menentukan kebijakan UMKM sehingga dapat meningkatkan nilai GDP secara nasional.

\section{KESIMPULAN DAN SARAN}

\section{Kesimpulan}

Struktur modal PT XYZ pada awalnya berasal dari setoran modal dan program pemerintah. Seiring dengan pertumbuhan usaha, perusahaan kemudian memperkuat struktur modal dengan melakukan leveraging melalui 
pinjaman lembaga keuangan dan instrumen pasar modal. Dari awal setoran modal sebesar Rp300 miliar di awal pendirian, sampai dengan tahun buku 2017 jumlah aset PT XYZ mencapai Rp10,4 triliun atau 35 kali lipatnya dari setoran modal, yang terdiri dari $\mathrm{Rp} 1,8$ triliun ekuitas dan Rp8,6 triliun liabilitas.

Terdapat dua parameter ukuran keberlanjutan PT XYZ; profit dan development agent. Penggunaan instrumen pasar modal sebagai sumber pendanaan optimal perusahaan memberikan pengaruh dan dampak yang positif pada kedua parameter tersebut. Dari sisi profit, penggunaan instrumen pasar modal terbukti secara historikal menghasilkan biaya yang relatif lebih rendah dibandingkan dengan instrument pendanaan lainnya. Sedangkan, dari sisi agent of development, adanya instrumen pasar modal ini akan memberikan kapasitas pendanaan bagi perusahaan untuk melakukan ekspansi bisnis UMKM.

Strategi utama yang dilakukan oleh PT XYZ adalah ekspansi bisnis dengan menambah jumlah kantor baru sehingga dapat menciptakan jumlah nasabah yang lebih banyak dan dapat memberikan banyak manfaat dalam pengembangan UMKM di Indonesia. Penentuan lokasi yang baik dengan mempertimbangkan beberapa aspek seperti adanya sektor riil masyarakat dan adanya infrastruktur dasar menjadi hal yang perlu diperhatikan. Berkaitan dengan strategi sumber pendanaan, maka isu terhadap modal kerja bisa diperoleh dari Penyertaan Modal Negara atau PMN yang dapat diberikan oleh pemegang saham dalam hal ini pemerintah secara berkelanjutan. Berdasarkan data Annual Report PT. XYZ tahun 2017 terdapat kegiatan pembinaan dan bimbingan UMKM nasabah PT. XYZ yang dilakukan oleh Divisi PKU. Jumlah kegiatan tersebut terdiri dari program kegiatan pelatihan dan pendampingan usaha sebanyak 1.115 kali pada seluruh wilayah operasional PT. XYZ di Indonesia dengan jumlah peserta dari kalangan UMKM sebanyak 41.273 peserta. Jumlah tersebut meningkat $47 \%$ dari tahun sebelumnya. Manfaat positif yang dirasakan nasabah melalui program PKU ini menjadikan program tersebut perlu tetap dipertahankan dan ditingkatkan, baik dari sisi kuantitas dan kualitas, karena program tersebut menjadi uniqueness PT. XYZ yang berbeda dari perusahaan lainnya. Adanya PT. PQR yang merupakan anak perusahaan PT. XYZ memiliki fungsi yang selaras dengan roadmap kementrian BUMN, yaitu mendirikan trading house bagi UMKM untuk membantu memasarkan produk UMKM. Hal tersebut menambah uniqueness dan kekuatan PT. XYZ.

\section{Saran}

Saran untuk regulator yaitu agar dapat memberikan kebijakan yang fleksibel dua arah (UMKM dan pelaku bisnis). Selain itu perlu adanya penelitian lanjutan mengenai capital structure pada lembaga keuangan non bank dengan bisnis microfinance. Saran lainnya bagi perusahaan berkaitan dengan isu DER, yang dapat dikendalikan dengan penambahan modal atau pengurangan utang, maka perusahaan bisa melakukan opsi untuk IPO.

\section{DAFTAR PUSTAKA}

Abrar A, Javaid AY. 2016. The impact of capital structure on the profitability of microfinance institutions. South Asian Journal of Management Sciences 10(1): 21-37. https://doi.org/10.21621/ SAJMS.2016101.03.

Alima S. 2015. Pengaruh struktur modal terhadap profitabilitas pada perusahaan industri tekstil dan garment yang terdaftar di bursa efek Indonesia. Jom FISIP 2(2): 1-13.

[BI] Bank Indonesia. 2018. Statistik Ekonomi dan Keuangan Indonesia (SEKI). https://www.bi.go. $\mathrm{id} / \mathrm{id} /$ statistik/seki/terkini/moneter/Contents/ Default.aspx [2018 Februari 10].

Bappenas. 2016. Warta KUMKM. https://www. bappenas.go.id/index.php/download_file/ view/22661/832 [2017 November 10].

Boutilda R. 2015. Analisis pengaruh struktur modal terhadap profitabilitas perusahaan (studi empiris perusahaan-perusahaan manufaktur yang terdaftar di BEI periode 2009-2013). Jurnal Fakultas Ekonomi-UI2015.

Bubic J, Susak T. 2016. Distinctive features of companies with optimal capital structure. 16th International Scientific Conference on Economic and Social Development - The Legal Challenges of Modern World - Split, 1-2 September 2016.

Dulababu T. 2016. Case study: an analytical study of the impact of capital structure on profitability of top it companies in India. Advances In Management 9(9): 6-13.

Fersi M, Boujelbéne M. 2017. Capital structure decisions of microfinance institutions and managerial behavioral biases: a survey and future directions. ACRN Oxford Journal of Finance and Risk Perspectives 6(1): 70-89.

Haninun, Angelina F. 2016. Pengaruh struktur 
modal terhadap profitabilitas pada perusahaan manufaktur yang terdaftar di BEI periode 20112013. Jurnal Akuntansi \& Keuangan 7(1): 7386.

Hasbi H. 2015. Islamic microfinance institution: the capital structure, growth, performance and value of firm in Indonesia. Procedia - Social and Behavioral Sciences 211(2015): 1073 - 1080. https://doi.org/10.1016/j.sbspro.2015.11.143.

Indayani, Ghozali I, Isgiyarta J. 2017. Capital structure, corporate governance and financial sustainability in microfinance. International Journal of Economic Research 14(14): 291-304

Johnson C. 2015. The Impacts of Capital Structure on Depth of Outreach in Sub-Saharan Africa. Working paper. Illinois State University. Spring 2015.

Kundid A. 2012. How much is the choice of capital structure important for bank profitability in Croatia? Zagreb International Review of Economics \& Business 15: 53-68.

Marusya P, Magantar M. 2016. Pengaruh struktur modal terhadap profitabilitas pada perusahaan tobacco manufacturers yang terdaftar di bursa efek indonesia (BEI) periode 2008-2015. Jurnal Berkala Ilmiah Efisiensi 16(03): 484-492.

Omare OS. 2017. Effect of capital structure on performance of microfinance institutions: a case of deposit taking microfinance institutions. International Journal of Business Management and Finance 1(7):105-120.

Sekabira H. 2013. Capital structure and its role on performance of microfinance institutions: the ugandan case. Sustainable Agriculture Research 2(3): $\quad 86-100 . \quad$ https://doi.org/10.5539/sar. v2n3p86.

Setiono O, Siregar H, Anggraeni L. 2017. Struktur modal dan modal kerja pt xyz serta pengaruhnya terhadap kinerja perusahaan. Jurnal Aplikasi Bisnis dan Manajemen 3(1): 131-142. https:// doi.org/10.17358/jabm.3.1.131.

Taqi M, Ajmal M, Pervez A. 2016. Impact of capital structure on profitability of selected trading companies of India. Arabian Journal of Business and Management Review (Oman Chapter) 6(3): 1-16. https://doi.org/10.12816/0033239.

Thalib D. 2016. Intermediasi, struktur modal, efisiensi, permodalan dan risiko terhadap profitabilitas bank. Jurnal Keuangan dan Perbankan 20(1): 116-126.https://doi.org/10.26905/jkdp. v20i1.155.

Violita RY, Sulasmiyati S. 2017. Pengaruh struktur modal terhadap profitabilitas (studi pada perusahaan food and baverages yang terdaftar di BEI tahun 2013-2016). Jurnal Administrasi Bisnis (JAB) 51(1): 138-144.

Warsawinangun RZ, Darminto, Nuzula NF. 2014. Penetapan struktur modal yang optimal dalam upaya meningkatkan nilai perusahaan. Jurnal Administrasi Bisnis 9(2): 1-8

Waweru MW, Wanyoike D. 2016. Effect of capital structure on profitability of microfinance institutions in Nakuru Town, Kenya. International Journal of Economics, Commerce and Management IV(10): 1144-1167. 